\title{
Revising the chronology of Stanovoye 4 in the Upper Volga Region (Western Russia)
}

\author{
Sandra Söderlind ${ }^{1}$, Mikhail Zhilin ${ }^{2}$ \\ 1 ROOTS Young Academy, Kiel University, Kiel, DE; ssoederlind@roots.uni-kiel.de \\ 2 Institute of Archaeology of Russian Academy of Sciences, Moscow, RU; mizhilin@yandex.ru
}

\begin{abstract}
This paper examines the Stanovoye 4 site-chronology, which was developed through several radiocarbon dating efforts throughout the last two decades. Today, the dates indicate longterm cultural traditions at the site, lasting over 3000 years. The goal of this paper is to understand the site chronology holistically, which is done through a critical review of all available dates and sample characteristics. Additionally, the choice of sample materials, dating methods and preservation practices will be discussed. Furthermore, the dating of PVA-consolidated samples is discussed from an archaeological standpoint.
\end{abstract}

KEY WORDS - radiocarbon dating; Mesolithic; Neolithic; chronology; the Upper Volga region

\section{Revizija kronologije najdišča Stanovoye 4 iz območja zgornjega toka reke Volge (zahodna Rusija)}

\begin{abstract}
IZVLEČEK - V članku predstavljamo kronologijo najdišč Stanovoye 4, ki je bila oblikovana v zadnjih dveh desetletjih na podlagi številnih radiokarbonskih datumov. Trenutni podatki kažejo, da je poselitev na najdišču del dolgotrajne, več kot 3000-letne kulturne tradicije. V članku poskušamo razumeti kronologijo najdišča na holistični način, in sicer spomočjo kritične recenzije vseh dostopnih datumov in značilnosti vzorcev. Poleg tega razpravljamo tudi o izboru materiala vzorcev, metodah datiranja in zaščitnih praksah. Ob tem iz arheološkega vidika obravnavamo tudi datiranje vzorcev, ki so bili utrjeni s PVA lepili.
\end{abstract}

KLJUČNE BESEDE - radiokarbonsko datiranje; mezolitik; neolitik; kronologija; območje zgornjega toka reke Volge

\section{Introduction}

The site Stanovoye 4, located in the Ivanovo area of the Upper Volga region, in western Russia, was excavated by Mikhail Zhilin, between the years 1992 and 2002. The site consists of four Mesolithic archaeological layers, a layer dating to the early phase of the so-called 'Forest Neolithic' (characterized by the presence of ceramic but without farming or pastoralism) as well as a Middle Neolithic layer. Because of the site's distinct and radiocarbon-dated stratigraphy, as well as good organic preservation conditions, its chronology and technological development can be explored in detail. Furthermore, the site's location in the centre of the Upper Volga region makes it relevant for studies of regional and transregional contacts and communications from the very beginning of the Mesolithic until the Middle Neolithic (Zhilin 2002; 2009).

The Upper Volga region is likely a relevant area for the spread of several technological concepts into Fennoscandia and northern Continental Europe during the Mesolithic (cf. Rankama, Kankaanpää 2007; 2008; Hartz et al. 2010; Sørensen et al. 2013; Kankaanpää, Rankama 2014; Damlien 2016; Manninen et al. 2021). The chronological bases for these technological dispersions rest on more than 150 
radiocarbon dates from around 30 sites, several of which are stratified peat bog sites (Zhilin 2009).

The Stanovoye 4 site has already been dated on several occasions: Nataliya Zaretskaya et al. (2005), Sönke Hartz et al. (2010), Bente Philippsen (2019) and most recently by the authors of this paper. In this article, we calibrate and evaluate all previously dated samples, along with the newly acquired dates. The large number of radiocarbon-dated samples, done during the last two decades, come with various source critical aspects. Here, we review the use of certain sample materials, varying dating methods and problematic preservation practices in order to explore and map the many source critical factors that play into the chronology of the Stanovoye 4 site, in an effort to better understand it.

This will be done by detangling various fractions of radiocarbon samples that are characterized by different source critical issues and instead use these fractions to create individual chronologies. After this (divide-and-conquer-like) procedure, the chronologies will be compared and evaluated to reach a general chronology for the site. This chronology, along with the stratigraphic and archaeological evidence from the site, will provide a more comprehensive understanding of human activities during the early Holocene.

\section{The site and stratigraphic sequences}

The Stanovoye 4 site is located on a sloping promontory stretching into the Podozerskoye peat bog, formed in the terrace of a previous glacial lake (Fig. 1).
The Lahost River runs from the bog and through the site. The stratigraphy at the site is complex with highly dynamic sedimentation processes, which also differ slightly across the site's two main trenches, i.e. trenches 2 and 3 (Fig. 2) (Zhilin 2002; 2009; Zhilin, Matiskainen 2003). A smaller trench (1) is situated c. 50 meters west of trench 2 (Zhilin 2002) but will not be dealt with here due to its small assemblage and lack of dates. The stratigraphies from trench 2 and 3 have been subject to sediment analysis and substantial plant microfossil analysis, which provided insights on the local sedimentation processes (Zaretskaya et al. 2005). Pollen analysis has also been useful for reconstructing the prehistoric environments surrounding the site (Aleshinskaya 2001).

\section{Environmental processes of sedimentation at the site}

The sediment layers that make up the site are numbered 1-9 and the archaeological layers are referenced by Roman numerals I-IV. The following sedimentation process at the site is based on the previous investigations by Anna S. Aleshinskaya (2001) and Nataliya E. Zaretskaya et al. (2005).

The stratigraphy and chronology of the site starts at the Early Mesolithic ground level, which consists of washed moraine. The artefacts found on top of this moraine are related to archaeological layer IV. At the time the site was situated on, and in the near vicinity of, the ancient shoreline. Due to rising water levels the site was later submerged and artefacts from archaeological layer IV became covered by sediment layer 8 . The analysed sedimentary samples

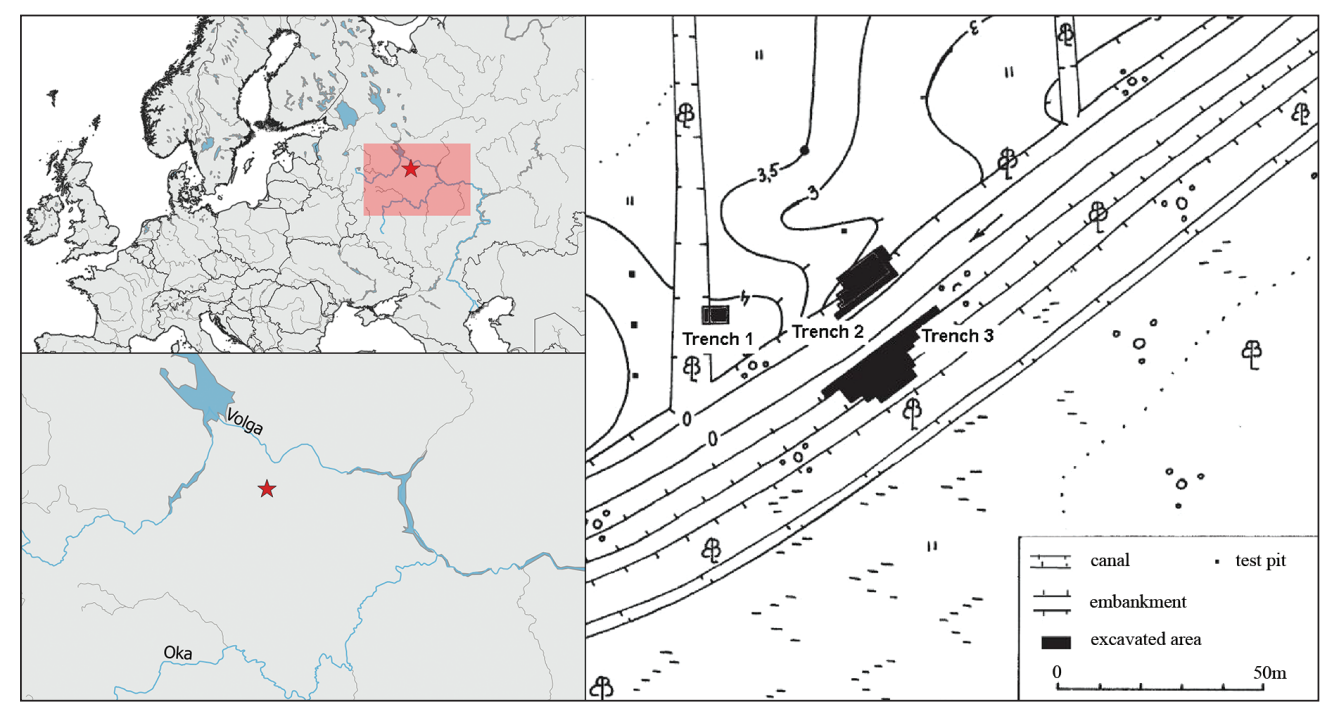

Fig. 1. On the left, a red star marks the location of Stanovoye 4 in Russia. On the right, plan of the site (@EuroGeographics for the administrative boundaries). 


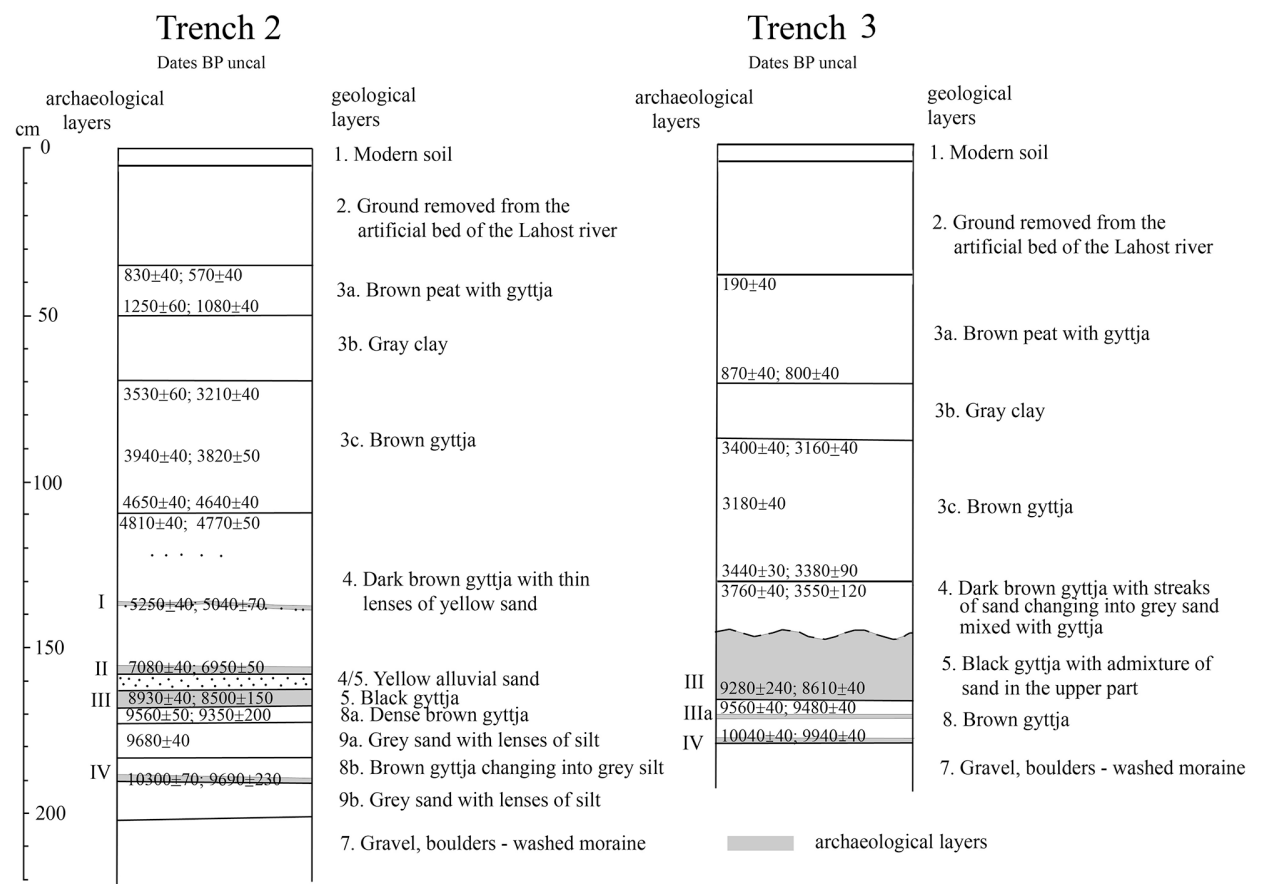

Fig. 2. Stratigraphies from trenches 2 and 3. Geological layers are numbered 1-9, and archaeological layers using roman numerals I-IV. ${ }^{4} \mathrm{C}$ ages are in uncal BP (see Table 1, available at http://dx.doi.org/ 10.4312/dp.48.13).

from layer 8 consist of organomineral silt and gyttja, which along with the plant compositions indicate that sedimentation took place in an environment characterized by cooler water temperatures (in trench 2) and shallow littoral sediments in the form of gyttja (in trench 3). The pollen and microfossil analyses, along with the acquired dates, thus suggest that sediment layer 8 and archaeological layer IV were deposited at the very end of the Younger Dryas and at the beginning of the Preboreal (Aleshinskaya 2001; Zaretskaya et al. 2005).

Gyttja (related to layer 8) continued to accumulate on top of layer IV in the following centuries. This is due to rising water levels of the nearby lake during the warmer temperatures at the beginning of the Preboreal. This is also supported by pollen and microfossil data (Aleshinskaya 2001; Zaretskaya et al. 2005).

Subsequent sediments, from the upper part of sediment layer 8 , in trench 3 , show that the water level of the nearby lake was reduced again in the context of a Preboreal landscape, as based on plant microfossils and pollen (Zhilin, Matiskainen 2003; Zaretska$y a$ et al. 2005). During this regression, archaeological layer IIIa was accumulated. About 100 years later, another transgression is visible in the sediments together with changes in river activity (Zaretskaya et al. 2005). In the same stratigraphic horizon, but in trench 2 , two thin wooden stakes were found be- tween the two archaeological layers IV and III ( $\mathrm{Zhi}$ lin 2002). This area of the stratigraphy will henceforth be referred to as sediment layer IV/III.

The obtained radiocarbon dates show a start of sedimentation of layer 8 in trench 3 in the first half of the 10th millennium cal $\mathrm{BC}$ and it continues until the first half of the 9th millennium. In trench 2 , the sedimentation of layer 8 is dated from the second half of the $10^{\text {th }}$ millennium to the second half of the $9^{\text {th }}$ millennium (Zaretskaya et al. 2005).

Archaeological layer III is embedded within sediment layer 5 in both trenches. In trench 3, pollens from this layer indicate that sedimentation took place during the second half of the Preboreal. Meanwhile, pollens from the same layer in trench 2 are characteristic of a landscape during the first half of the Boreal (Aleshinskaya 2001). The radiocarbon dates obtained from trench 3 show a start of sedimentation of archaeological layer III around the middle of the $9^{\text {th }}$ millennium, continuing into the first half of the $8^{\text {th }}$ millennium cal BC. In trench 2 , the sedimentation of layer 5 is instead dated to the end of the $9^{\text {th }}$ millennium and continuing into the second half of the $8^{\text {th }}$ millennium cal BC (Zaretska$y a$ et al. 2005).

The sediment layer $4 / 5$ in trench 2 consists of yellow sand, which contains redeposited artefacts that 
probably come from layer III. This layer is interpreted as relating to a series of flooding events, in which finds were washed out from the slopes of the promontory (situated north of trench 2), moved downstream and subsequently redeposited in the riverbanks. Pollen analysis of related sediments in trench 2 indicates that this occurred during the second half of the Boreal. Later on, the lake level again rose, covering layer $4 / 5$ (in trench 3 ) with gyttja. The bottom part of this gyttja layer contains archaeological layer II, preserved in situ. Pollen data from this layer indicate sedimentation during the Early Atlantic period (Aleshinskaya 2001; Zhilin, Matiskainen 2003). Radiocarbon dates from the bottom part of the gyttja layer (layer 4 in trench 2) indicate that this sedimentation started in the first half of the $6^{\text {th }}$ millennium cal BC and continued throughout the following centuries (cf. Zaretskaya et al. 2005). The Middle Neolithic layer I in trench 2 is embedded in gyttja, which was deposited during the Atlantic period (Aleshinskaya 2001).

\section{Cultural and technological traditions at the site}

The earliest settlement phase on the Stanovoye 4 site is represented by archaeological layer IV, in both trenches. The archaeological materials consist of 154 lithic artefacts and $c .54$ bone and antler tools. The typology and technology of these finds indicate that they belonged to the Early Mesolithic Butovo technocomplex (cf. Zhilin, Matiskainen 2003; Zhilin 2007; 2009).

Artefacts from this layer showcase a variety of technological concepts and techniques. The production of larger blades was done by means of indirect (punch) techniques while smaller blades were produced using pressure techniques from a variety of core types (Zhilin 2009; Hartz et al. 2010). Bone and antler artefacts were made from a variety of animal species, including elk and beaver (Zhilin 2003; 2007; 2009; Zhilin, Matiskainen 2003).

The subsequent archaeological layer is found solely in trench 3 and is represented by layer IIIa. The related lithic assemblage is scarce but includes a few chert flakes, a flint knife, an asymmetric trapeze and an oblique one-edged arrowhead, the latter characteristic of the Ienevo technocomplex, although the round scrapers from this layer are typical for the $\mathrm{Bu}$ tovo technocomplex. The bone and antler assemblage includes artefacts such as a large arrowhead with an irregular sub-biconical head, a gouge, a fragment of a knife and a grooved long bone. Other or- ganic finds include the remains of a wooden fish trap found with a large stone sinker adjacent to it (Zhilin, Matiskainen 2003).

The following settlement period is represented by archaeological layer III, found in both main trenches. This assemblage shows typological and technological features related to the Middle Mesolithic period, and the Butovo technocomplex, as described above (Zhilin 2003; 2007; 2009; Zhilin, Matiskainen 2003). The bone and antler assemblages from this layer are extensive, including a variety of tools and artefacts, along with many wooden stakes which have been interpreted as fishing weirs ( $c f$. Zhilin, Matiskainen 2003).

Archaeological layer II was recovered only in trench 2. Its assemblage includes a small number of flint and bone finds as well as thick-walled ceramic fragments. This suggests the presence of an economy based on hunting, gathering and fishing as well as the use of pottery, which is characteristic of the earliest stage of the Early Neolithic Upper Volga cultural complex (Zhilin, Matiskainen 2003).

Archaeological layer I was excavated in trench 2. It yielded several Middle Neolithic flint artefacts and small bone fragments (Zhilin 2002).

\section{Materials and methods}

A total of 49 radiocarbon samples are currently available from the Stanovoye 4 site (Tab. 1; available at http://dx.doi.org/10.4312/dp.48.13). These include four artefact samples (see Fig. 3) that have not been published previously. In an effort to understand the characteristics of the samples, aspects of storage and sampling will be described. The methods involved in the sample subgrouping will also be explained.

\section{During and after excavation}

During excavation, finds and samples were stored in plastic bags. After the excavations the organic remains were cleaned with water and subsequently dated or stored. Some of the wooden and organic samples were dated shortly after excavation (and published by Zaretskaya et al. 2005), while other samples were consolidated using one layer of a (10\%) PVA solution made up of water and carpenter's glue (bought in the late 1990s). After the consolidation samples were stored in plastic bags.

Two fragments of wooden handles (KIA-35153 and KIA-35157) that were found inside antler mattocks 
(sleeves) were put in plastic bags, while still wet, and kept there for a decade before being dated. According to Leopold D. Sulerzhitsky (personal communication) such a situation can lead to modern carbon being introduced into samples from surrounding air as a result of fungal activity inside the wood. There is therefore a possibility of modern contamination in these samples.

\section{Sampling and dating of artefacts}

The sampling of artefacts from the site has mainly been done by Mihail Zhilin who followed a procedure that starts by mechanically removing the surface of the bone artefacts in the area of sampling, in an active effort to avoid any surface contaminators. For some artefacts, such as larger antler sockets, a layer of up to $3 \mathrm{~mm}$ of the surface was removed. Subsequently, a hole was drilled into the interior of the bone, creating the bone powder used for dating. For other artefacts, such as smaller and more delicate beaver mandibles, the surfaces were more lightly scraped off before drilling. Some artefacts were, however, sent to the lab for cleaning and sampling (and subsequently published by Hartz et al. 2010).

Samples have been dated at different times and by various labs, including the Geological Institute at the

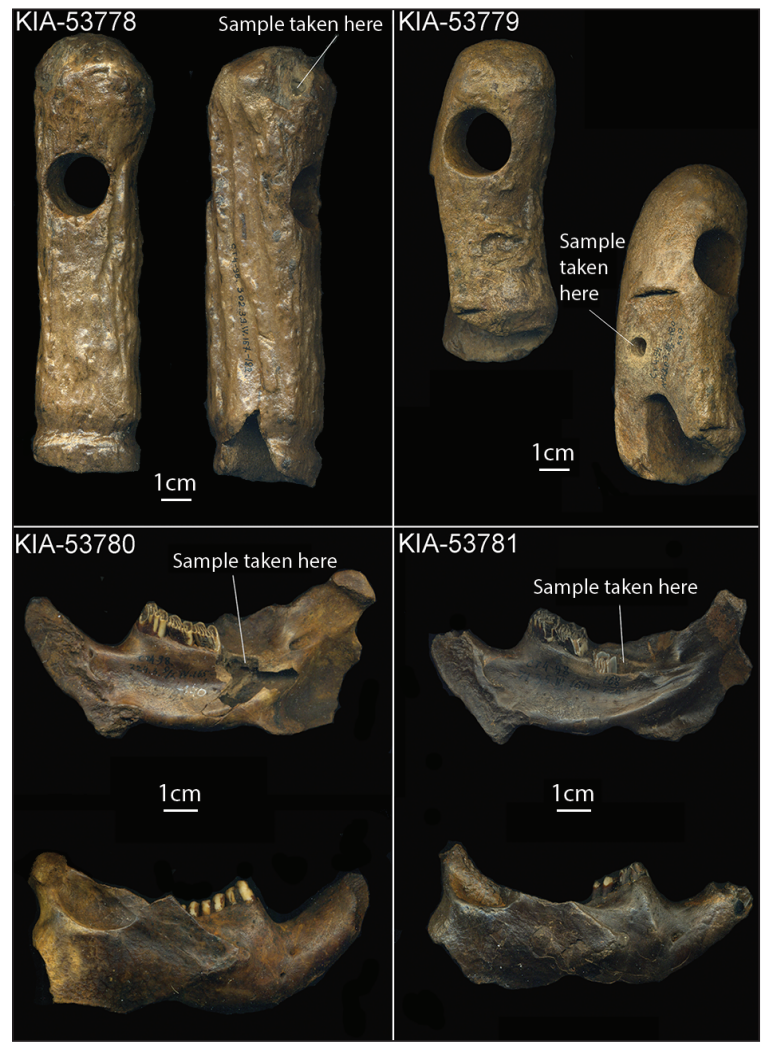

Fig. 3. The newly dated artefacts.
Russian Academy of Sciences (RAS) (lab-code GIN), Leibniz Laboratory for Radiometric Dating and Stable Isotope Research in Kiel (lab-code KIA), Aarhus AMS centre (lab-code AAR) and the Groningen AMS lab (lab-code GrA). The newly dated radiocarbon samples were also dated at the lab in Kiel. The different labs follow similar protocols for preparing/cleaning the samples and collagen extraction (for individual lab procedures, see Appendix below).

The samples were calibrated using the most recent r:5 Atmospheric IntCal20 dataset (Reimer et al. 2020 ) in Oxcal v 4.4 .2 (Bronk Ramsey 2021).

\section{Subgrouping the samples}

In an effort to exclude certain source critical issues, relating to various sample materials, dating methods and consolidation efforts, the samples will be subgrouped into different datasets. Each dataset will subsequently undergo calibration and individual chronologies will be presented, before a more general chronology for the site is discussed.

The attribution of samples in different datasets (Tab. 2) needs to be addressed. All samples are attributed to one of the following datasets: 1 (sediments), 2 (artefacts) or 3 (ecofacts). Each sample can be clearly attributed to one of these groups. However, for datasets 4-7, it is possible to find individual samples in several datasets, since one sample can be both AMS-dated (dataset 4) and consolidated (dataset 7).

\section{Excluded samples}

Some of the previously dated sediment samples underwent both cold and warm extractions, resulting in two dates for each sample (as noted in Table 1; available at http://dx.doi.org/10.4312/dp.48.13). These were sometimes not in agreement. In this study, we decided to use the dates from the warm extraction whenever the two fractions did not agree (see Appendix below).

\section{Reviewing and calibrating the datasets}

\section{Dataset 1 - Sediments}

Sediment samples and source critique

The dataset includes samples of silt and gyttja. These samples were $2-4 \mathrm{~cm}$ thick and were extracted from the trench wall. In general, the use of sediments such as gyttja, silt and peat for radiocarbon dating has been criticized for several reasons, mainly due to the complexity of sedimentation processes and different potential origins of the accumulated carbon in 
a small sample (Zaretskaya et al. 2001; Taylor, BarYosef 2014.91-92).

An issue relating to the sediment samples from Stanovoye 4 is the small representation of samples, with only a few samples from each layer. Moreover, despite the sediment layers containing archaeological materials/layers, the sediments themselves are not anthropogenic remains. Therefore, they don't directly date the occupational phases or human activities on the site.

\section{Calibrated sediment dates}

Based on the sediment dates from Stanovoye 4 (Fig. 4), the acquired site chronology seems to reflect 45 phases in a longer continuous sedimentation process. The samples from layer IV date to the final stages of the Younger Dryas and first half of the Preboreal, spanning $10500-9300 \mathrm{cal} \mathrm{BC}$. The two oldest dates have extensive standard deviations, amounting to 500-600 years, making an exact starting point for habitation difficult to interpret.

The samples from sediment layer IV/III date to the Preboreal, specifically between 9300 and 8700 cal BC. Samples from layer III seem to divide into two clusters, one at around 8300-7900 cal BC and another at $7800-7500 \mathrm{cal} \mathrm{BC}$. However, there are too few samples to confidently argue for two separate occupational phases. Lastly, samples from layer II date to the Atlantic period, to $c$. $6600-5800 \mathrm{cal} \mathrm{BC}$.

\section{Dataset 2 - Artefacts}

Artefact samples and source critique

The artefacts from the site include bone and antler artefacts as well as worked wooden handles and stakes. In general, bone and antler samples come with a number of source critical aspects. For instance, aquatic animals and marine-feeding animals can store higher amounts of aquatic carbon in their bones, resulting in an apparently older date, known as the marine/freshwater reservoir effect (Philippsen 2013; Taylor, Bar-Yosef 2014.71-74).

The dated bone samples from Stanovoye 4 do not include any aquatic fauna that can be subject to the marine/freshwater reservoir effect. Nevertheless, many of the dated bones and antler samples come from elk (Alces alces), which is a species that has been argued to be at risk of the freshwater reservoir effect due to their high consumption of aquatic plants (Philippsen 2019). Further research on this topic, which also included some finds from Stanovoye 4, has indicated little evidence for this relationship in general, although the finds from the site did suggest some temporal differences between an elk antler socket and its wooden handle (cf. Philippsen 2019). However, other reasons than the freshwater reservoir effect have been proposed for this (ibid.). These finds will also be discussed later in this article. Other dated bones from Stanovoye 4 include beaver (Castor fiber), which is a semi-aquatic animal with a terrestrial diet that can be excluded from the risk of the freshwater reservoir effect.

\begin{tabular}{|c|c|c|}
\hline Dataset & Contents & Included samples \\
\hline 1. Sediment samples & Silt and gyttja samples. & $\begin{array}{l}\text { GIN-8379, GIN-1011 II, GIN-10126 II, GIN-10106 II, GIN-10112 II, } \\
\text { GIN-10127 I, GIN-10108 II, GIN-10122 II, GIN-10127 II, GIN-10109 II, } \\
\text { GIN-10125 II, GIN-10110 II, GIN-10126 I }\end{array}$ \\
\hline $\begin{array}{l}\text { 2. Artefact/ } \\
\text { anthropogenic } \\
\text { samples }\end{array}$ & $\begin{array}{l}\text { Bone/antler artefacts } \\
\text { and one unworked } \\
\text { human bone. } \\
\text { Worked wooden finds. }\end{array}$ & $\begin{array}{l}\text { AAR-22231, GIN-8854, KIA-35157, AAR-22232, GIN-8856, KIA-35158, } \\
\text { GIN-8374, GrA-34084, KIA-39316, GIN-8375, KIA-35152, KIA-39317, } \\
\text { GIN-8376, KIA-35153, KIA-53778, GIN-8377, KIA-35154, KIA-53779, } \\
\text { GIN-8378, KIA-35155, KIA-53780, GIN-8853, KIA-35156, KIA-53781 }\end{array}$ \\
\hline 3. Ecofact samples & Unworked bone/wood & GIN-10113, GIN-10128, GIN-11093a \\
\hline 4. AMS-dated samples & $\begin{array}{l}\text { Artefacts dated } \\
\text { using AMS. }\end{array}$ & $\begin{array}{l}\text { AAR-22231, KIA-35155, KIA-53778, AAR-22232, KIA-35156, KIA-53779, } \\
\text { GrA-34084, KIA-35157, KIA-53780, KIA-35152, KIA-35158, KIA-53781, } \\
\text { KIA-35153, KIA-39316, KIA-35154, KIA-39317 }\end{array}$ \\
\hline $\begin{array}{l}\text { 5. Conventional dated } \\
\text { samples }\end{array}$ & $\begin{array}{l}\text { Artefacts and ecofacts } \\
\text { dated using conventional } \\
\text { dating methods. }\end{array}$ & $\begin{array}{l}\text { GIN-8374, GIN-8378, GIN-10113, GIN-8375, GIN-8853, GIN-10128, } \\
\text { GIN-8376, GIN-8854, GIN-11093a, GIN-8377, GIN-8856 }\end{array}$ \\
\hline $\begin{array}{l}\text { 6. Non-consolidated } \\
\text { samples }\end{array}$ & $\begin{array}{l}\text { Artefacts and ecofacts } \\
\text { that were not } \\
\text { consolidated. }\end{array}$ & $\begin{array}{l}\text { GIN-8374, GIN-8853, GIN-11093a, GIN-8375, GIN-8854, GrA-34084, } \\
\text { GIN-8376, GIN-8856, KIA-35153, GIN-8377, GIN-10113, KIA-35157, } \\
\text { GIN-8378, GIN-10128, KIA-39317 }\end{array}$ \\
\hline $\begin{array}{l}\text { 7. Consolidated } \\
\text { samples (PVA) }\end{array}$ & $\begin{array}{l}\text { Artefacts that were } \\
\text { consolidated. }\end{array}$ & $\begin{array}{l}\text { AAR-22231, KIA-35155, KIA-53778, AAR-22232, KIA-35156, KIA-53779, } \\
\text { KIA-35152, KIA-35158, KIA-53780, KIA-35154, KIA-39316, KIA-53781 }\end{array}$ \\
\hline
\end{tabular}

Tab. 2. The dated samples from Stanovoye 4 are attributed to seven different datasets, characterized by sample material, dating method and consolidation efforts. Note that each sample can be attributed to several datasets. 
A human bone (GrA-34084) was also included into the group due to its direct connection with human activity at the site. Since Stanovoye 4 is located far away from any marine environment, the marine reservoir effect can be excluded from the human bone. However, due to the site's location on the shore of the nearby lake, a risk of a freshwater reservoir effect in the human bone could be considered (Philippsen 2013; Meadows et al. 2020).

However, we assume that the dated human bone from Stanovoye 4 was not affected by the freshwater reservoir effect as suggested by the isotope value $\left(\delta^{13} \mathrm{C}=-21.08 \% \%\right)(c f$. Alexandrovskiy et al. 2009$)$. Additionally, the large amounts of mammal bones and smaller amounts of fish bones found in the same layer as the human bone (layer III, trench 3) has led to the interpretation that fish played only a minor part in the diet of the site inhabitants at that time (Zhilin 2004).

Generally, wooden artefacts can show an old-wood effect. This means that an artefact can appear older than its actual age since it is made up of several years' worth of tree growth and corresponding ages (Taylor, Bar-Yosef 2014.67-68). The dated wooden artefacts from Stanovoye 4 include several worked stakes (often made of birch), which vary between 6 and $10 \mathrm{~cm}$ in diameter. Additional finds include a plank which is $1.2 \mathrm{~m}$ long and $2 \mathrm{~cm}$ thick and sever- al handles (for antler sockets) which are $2-3 \mathrm{~cm}$ in diameter. The wooden artefacts from Stanovoye 4 were probably not affected by the old wood effect due to their smaller sizes and fast-growing wood species.

Wooden stakes in general come with some additional contextual ambiguity as they tend to pierce several stratigraphic layers and archaeological contexts. This can make their exact contextual information difficult to assume, which decreases their contextual reliability compared to other artefacts. The stratigraphic positions of dated stakes from Stanovoye 4 are clearly defined, and their relationships with archaeological layer III (in both trenches) are reliable (Zhilin 2003). The dated wooden handles are at risk of modern contamination due to the way they were stored prior to dating (as previously mentioned).

\section{Calibrated artefact dates}

The calibrated artefact samples from Stanovoye 4 (Fig. 5) suggest a more or less continuous chronology at the site. Samples from layer IV span a time between 10000 and $8700 \mathrm{cal} \mathrm{BC}$. The oldest date displays a very large standard deviation, making the start of this phase imprecise. Some samples from layer IV match the age of two wooden stakes found in layer IV/III (GIN-8374 and GIN-8376) as well as a wooden stake, lying horizontally, in layer IIIa (GIN8377). This is likely a result of the calibration curve

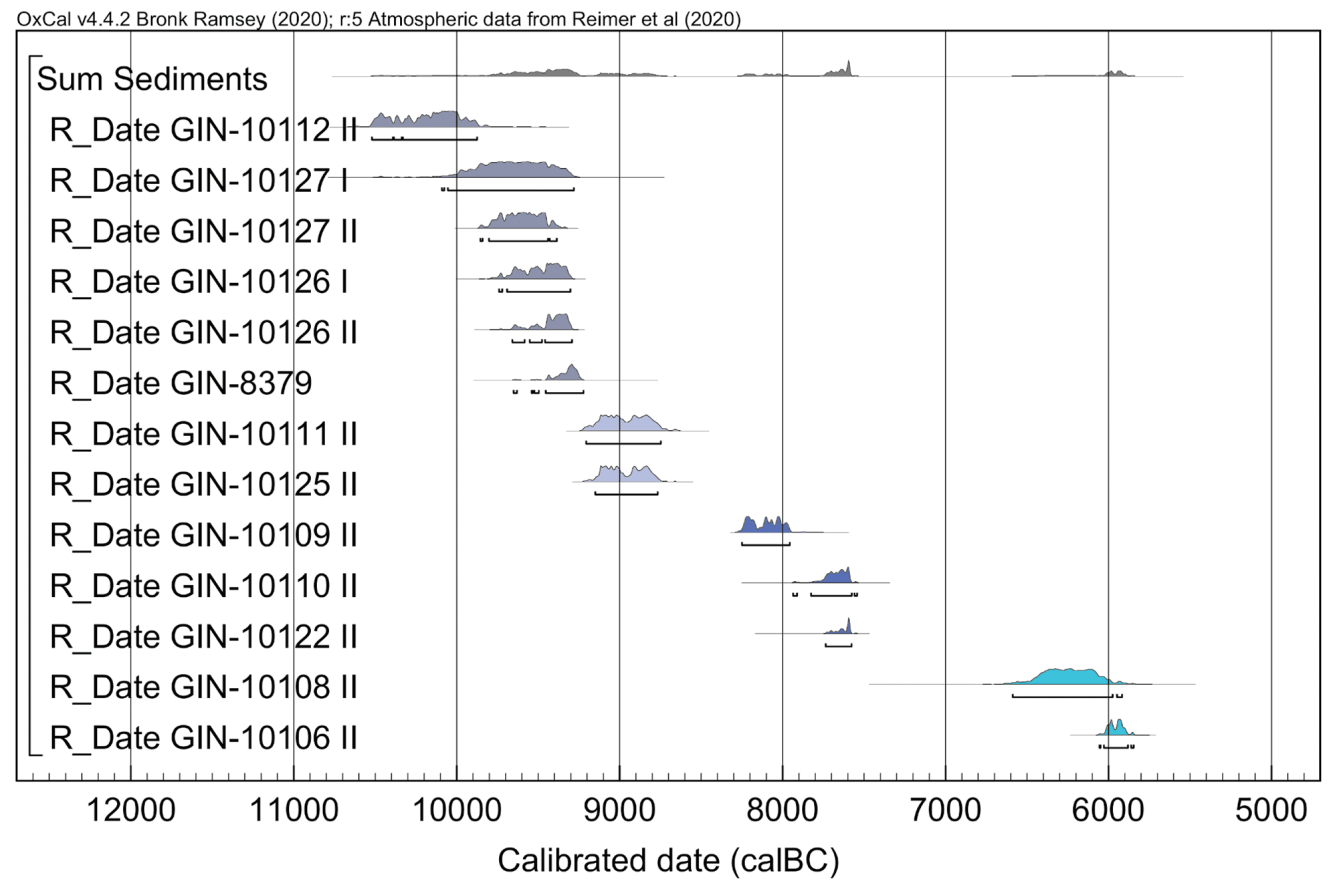

Fig. 4. Calibrated sediment samples from the site. The colours indicate their find contexts: grey archaeological layer IV; light blue layer IV/III; dark blue archaeological layer IIIa; blue archaeological layer III, and turquoise archaeological layer II. 
plateaus at this time, and would indicate that the age of several of the artefacts from layer IV are not significantly older than the stakes from layer IV/III.

One other sample (KIA-53780) from layer IV is much younger than the remaining samples from that layer. In fact, it instead coincides perfectly with the samples from layer III. Perhaps the sample's contextual information was incorrectly documented, and should instead place the find in layer III. Another possibility is that the find represents a younger intrusion in older layers.

The samples from layer III suggest a long chronology, between 8800 and 7200 cal BC. The samples cluster in several groups throughout the time period, likely due to the character of the calibration curve.

One artefact sample from layer II (GIN-8378) provides a date at around 6100-5700 cal BC, placing it in the Neolithic period.

\section{Dataset 3 - Ecofacts}

Ecofact samples and source critique

Only three samples are included in this group, all of which are unworked (i.e. not altered by humans). The sample GIN-10128 come from a piece of birch trunk (diameter $12 \mathrm{~cm}$ ), the sample GIN-10113 is a wooden branch with a $6 \mathrm{~cm}$ diameter and sample GIN-11093a was taken from an elk bone. Since the ecofacts are unworked they do not necessarily reflect human activities on the site. Additionally, the latter sample is the sole ecofact sample found within a clear archaeological layer (III, in trench 3). The sample GIN-10128 was found in a sterile interlayer between archaeological layers IV and III in trench 2, while the sample GIN-10113 pierced several layers, probably as a result of a tree fall (Zaretskaya et al. 2001).

Wooden samples are, as always, at risk for old wood effect. Though, the samples ages of the ecofact samples at Stanovoye 4 are probably not high enough to significantly alter the chronology of the site. The same can be said about the unworked elk bone which also has an unknown age, but should not be older than 25 years (maximum average age of European elk).

\section{Calibrated ecofact dates}

The ecofact samples suggest a very limited chronology (Fig. 6), based on the few available samples. The sample GIN-10128, from layer IV/III, dates to around 9300-8800 cal BC. From the same layer, sample GIN10113 instead dates to $c$. 8200-7600 cal BC, which more closely matches the final ecofact date from sample GIN-11093a. This sample comes from layer III and matches the sediment samples from the same context, dating to 8200-7600 cal BC. Sample GIN10113 possibly represents a younger intrusion into older layers.

\section{Dataset 4 - AMS dates}

AMS-dated samples and source critique

AMS-dated samples are generally more precise than conventionally dated samples (Bronk Ramsey et al. 2004), which makes this dataset support a more detailed chronology in general. Additionally, the finds from the site that were prioritized for AMS-dating are all artefacts and, thus, directly related to anthropogenic activities. The samples within dataset 4 are therefore characterized by both a strong contextual integrity and archaeological reliability.

A critical aspect of this dataset is the lack of samples from archaeological layers IIIa and II. Additionally, most of the AMS-dated samples have been consolidated using PVA-glue which increases the risk of contamination (more on this in Dataset 6).

\section{Calibrations of AMS-dated samples}

The AMS-based chronology (Fig. 7) is almost identical to the previously described artefact chronology (see Dataset 2). To summarize, archaeological layer IV dates to between $10000 \mathrm{cal} \mathrm{BC}$ and $8700 \mathrm{cal}$ $\mathrm{BC}$, while layer III starts around $8800 \mathrm{cal} \mathrm{BC}$ and ends sometime between 8300 and $7200 \mathrm{cal} \mathrm{BC}$.

\section{Dataset 5 - Conventional dates}

Conventionally dated samples and source critique The samples that were dated conventionally are all ecofacts or wooden stakes. As already mentioned, unworked ecofacts do not necessarily date anthropogenic activities on the site.

\section{Calibrations of conventionally dated samples}

The chronology, based on conventionally dated samples (Fig. 8), suggests that the oldest dates from the site come from layers IV/III and IIIa. These together span 9300-8800 cal BC. Although these dates do not represent the oldest settlement of the site, it appears that way since all dates from older layers were AMS-dated.

One sample from layer IV/III groups with samples from layer III, as was observed in dataset 3 . The samples from layer III span 8600-7500 cal BC. A sample from layer II is much younger than the remaining samples and dates to $6100-5700 \mathrm{cal} \mathrm{BC}$. 


\section{Dataset 6 - Non-consolidated samples}

Non-consolidated samples and source critique The non-consolidated samples can be excluded from the risk of PVA contamination (see Dataset 7). However, other source critical aspects relate to these samples. For instance, samples consist of both ecofacts and artefacts, which vary in the level of anthropogenic relation. Additionally, the non-consolidated samples were dated using either AMS or conventional dates, resulting in mixed levels of precision.

\section{Calibrations of non-consolidated samples}

The non-consolidated samples (Fig. 9) group in several clusters. The first cluster of dates includes samples from layers IIIa and IV/III, which together span 9300-8800 cal BC. The two samples from layer IV, falling within the same cluster, are discussed later on. The samples from layer III group into several clusters, although this is probably a result of the calibration curve plateaus. It is likely that the samples from layer III represent a continuous settlement on the site from around 8700 until $7500 \mathrm{cal} \mathrm{BC}$, as seen in the other datasets. The one sample from layer II dates the layer to $c \cdot 6100-5700 \mathrm{cal} \mathrm{BC}$.

\section{Dataset 7 - Consolidated samples}

Consolidated samples and source critique

The consolidated samples are all AMS-dated, making them more precise than conventional dates. The AMS dates based on artefacts are also directly related to anthropogenic activities on the site. Unfortunately, all these samples come from only two of the archaeological layers, IV and III, while the remaining layers lack representation.

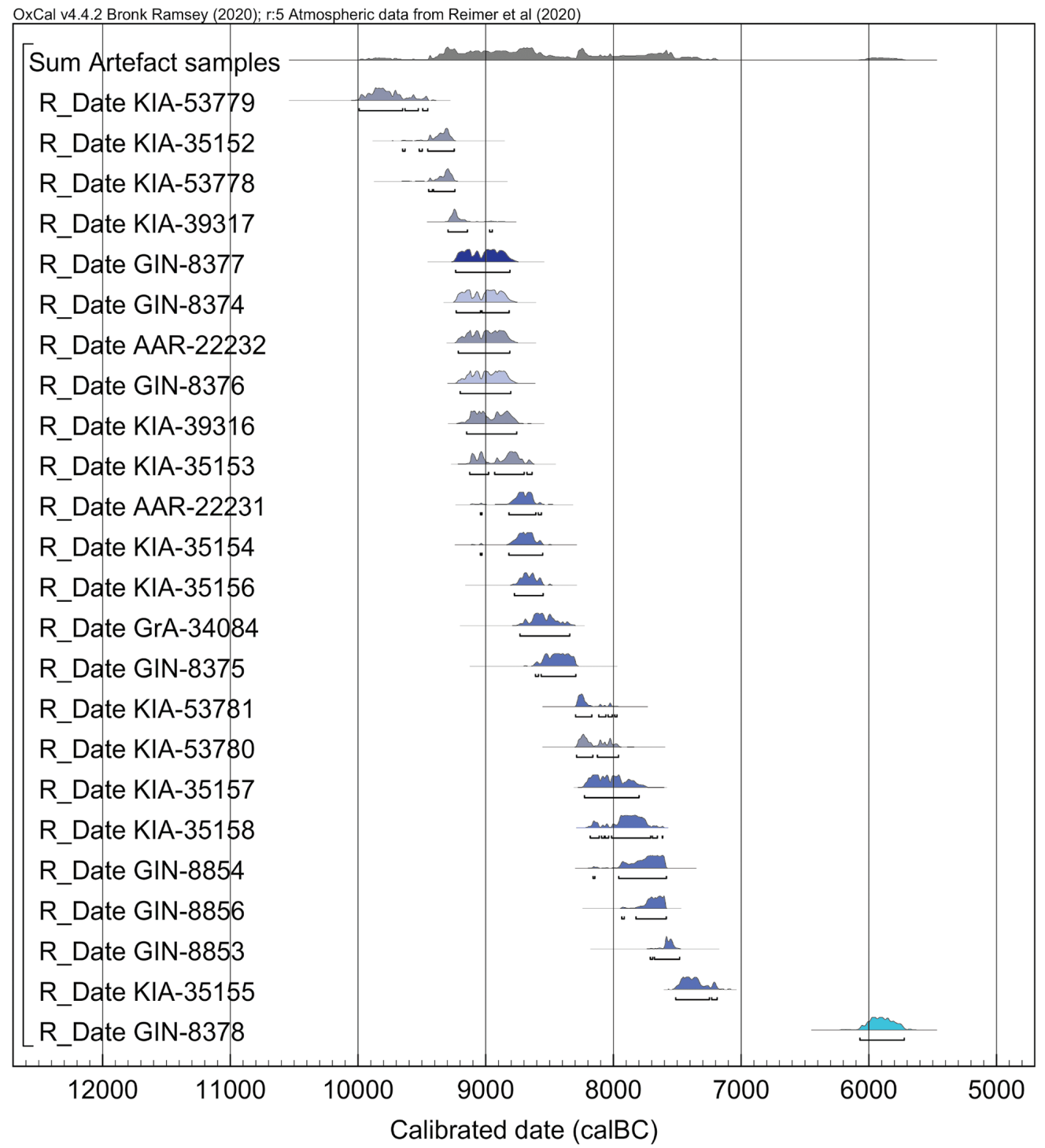

Fig. 5. Calibrated artefact samples from the site. The colours indicate their find contexts: grey archaeological layer IV; light blue layer IV/III; dark blue archaeological layer IIIa; blue archaeological layer III, and turquoise archaeological layer II. 


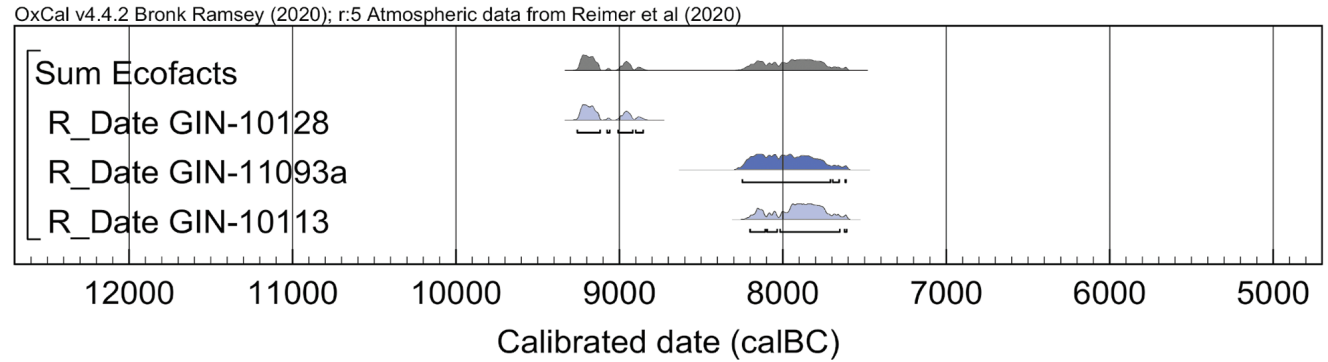

Fig. 6. Calibrated ecofact samples from the site. The colours indicate their find contexts: grey archaeological layer IV; light blue layer IV/III; dark blue archaeological layer IIIa.

Several organic samples from the site were preserved using PVA-glue. This practice has been common since the 1950 s, especially for finds from waterlogged sites. Many PVA-based consolidants exist, including PVA, PVAc and PVAL, but the most commonly used variety is known as 'Elmer's carpenter's glue'. Early studies showed that the glue could be easily removed in the lab prior to dating. However, in more recent years, studies have indicated that it might be harder to remove than initially thought. The reason is that PVA will form cross-linking of polymers which, over time, reduces its solubility (Johnson 1994).

An additional issue is that the details surrounding consolidation efforts are rarely documented. Often, it is not known which PVA-variety was used or how the treatment was carried out. This is an issue, since the details of these procedures play a role in the successful removal of the consolidant. Furthermore, the porosity of the artefact may also affect the solubility of the PVA (cf. Brock et al. 2018).

The reliability of the samples, and the related dates, depends on the successful removal of PVA, since remains can result in dates appearing older than they actually are. There are various strategies for removal of PVA-contaminants in the lab, most of which include the use of repeated washes of distilled water, acetone and methanol (as suggested by Stevens, Hedges 2004). The samples from Stanovoye have undergone similar treatments (see Appendix below).

However, several standard pre-treatments involving acetone, chloroform and methanol have in some stu-

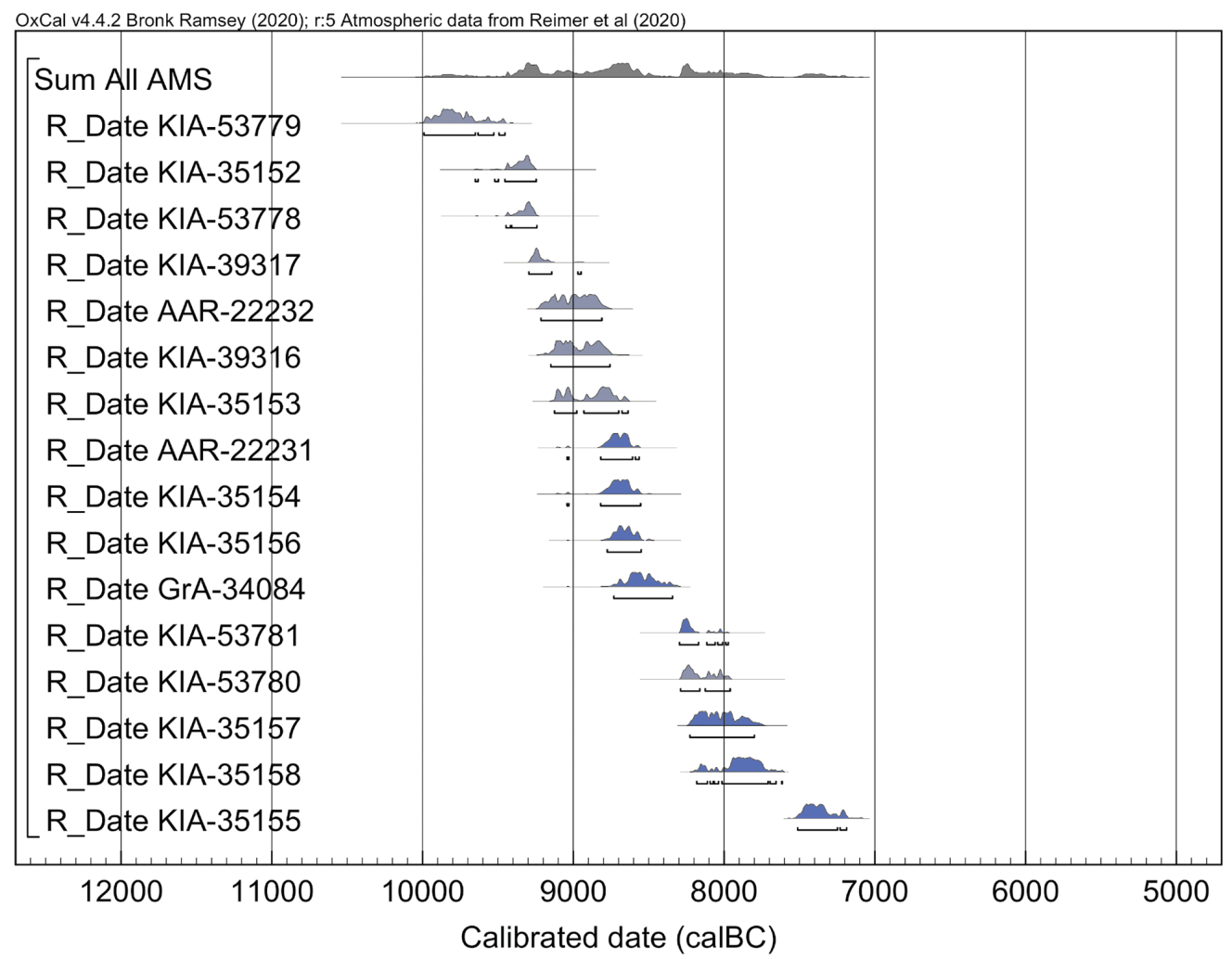

Fig. 7. Calibrated AMS-dated samples from the site. The colours indicate their find contexts: grey archaeological layer IV; dark blue archaeological layer IIIa. 
dies proven ineffective for removing common consolidants (Dee et al. 2011; Brock et al. 2018). Therefore, the dating of PVA-treated finds is not recommended unless alternative methods can be applied or the consolidated areas can be avoided (ibid.). The results by Fiona Brock et al. (2018) have been criticized due to their use of modern PVA-glue (often containing plastics and other additives), which may not be relevant for consolidation efforts in the past (Meadows et al. 2019). Additionally, the use of the silica-polymer Chromosorb ${ }^{\mathrm{TM}}$ (as a base for contamination experiments) might not correctly map the potential chemical cross-linking between the consolidant and the sample itself, due to the material's highly absorbent properties (Dee et al. 2011).

The use and removal of older consolidants on actual (Mesolithic) bone artefacts has recently been investigated (Meadows et al. 2019). Although the investigated bones turned out to not be consolidated using PVA, the other preservation mediums were found to have penetrated into the bone, while the highest concentrations were found on the surface ( $i b i d$.). If this is true also for PVA-consolidants, it could mean that the Stanovoye samples from further within the bone contain lower amounts of remaining PVA-contamination compared to samples from just beneath the surface.

The issues relating to the treatment and removal of PVA-glue from artefacts are clearly complicated. The PVA-treated artefacts from Stanovoye must be consi- dered somewhat less reliable, since lab pre-pre-treatments may not be as reliable for PVA-removal as previously indicated. If the consolidated samples from the site are affected by any remaining PVA, they could appear older than non-consolidated samples from the same contexts.

\section{Calibrations of consolidated samples}

The PVA-consolidated samples from Stanovoye 4 (Fig. 10) provide a very similar chronology to the AMS-dated samples, mainly due to the fact that the two chronologies largely consist of the same selection of samples. Nonetheless, the consolidated samples also follow the chronology suggested by the non-consolidated samples. The consolidated samples from layer IV span the time $10000-8700 \mathrm{cal} \mathrm{BC}$, although with few overlapping dates. Samples from layer III follow the already described pattern, which likely represents a long-term occupation on the site between 8800 and $7200 \mathrm{cal} \mathrm{BC}$.

The samples AAR-22232 and KIA-53778 come from the same artefact, an elk antler socket, which was consolidated using PVA. The AAR-sample was the first to be extracted and the KIA-date was taken from the same area but from further within the artefact. The wooden handle that belongs to the same artefact was not consolidated, but also dated (KIA-35153). However, this sample instead poses a risk of modern contamination due to incorrect storage after excavation. A comparison of the samples can be found in Table 3.

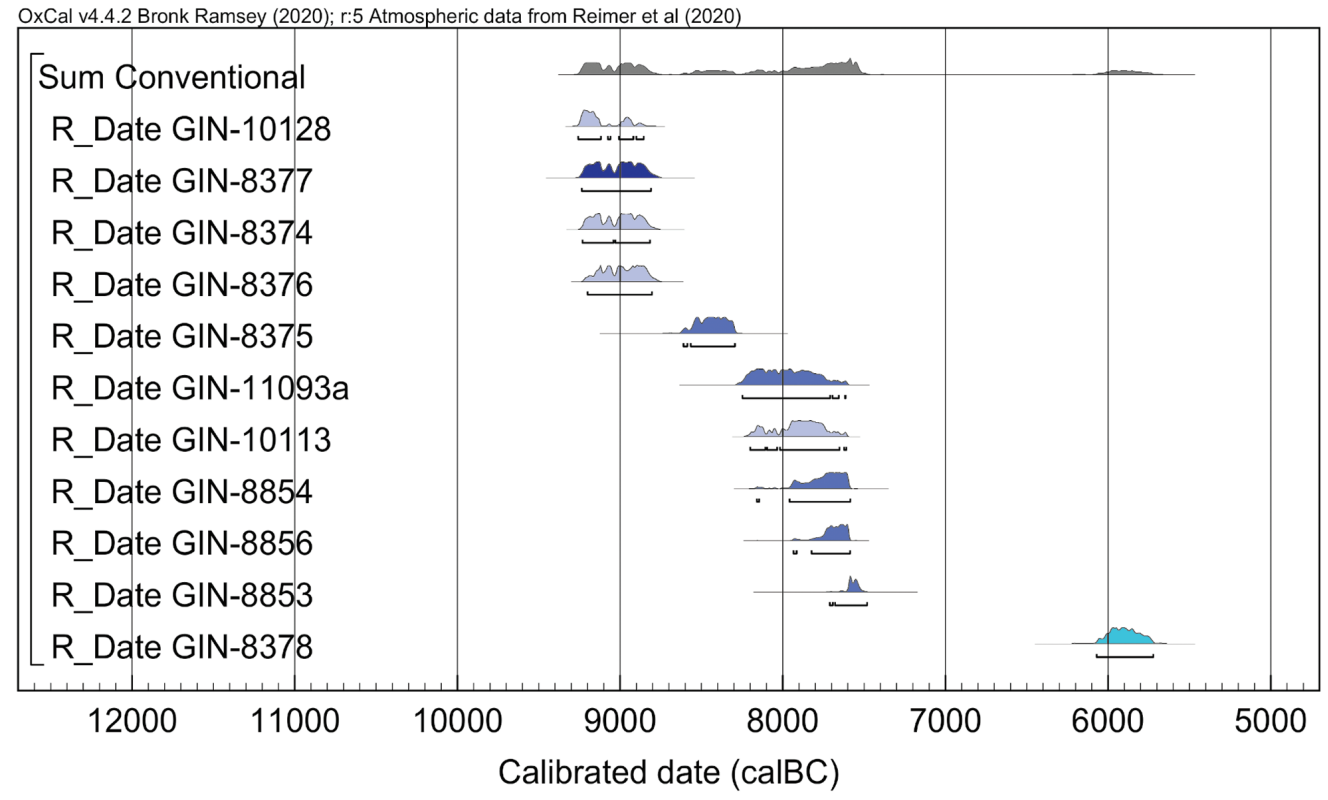

Fig. 8. Calibrated conventionally dated samples from the site. The colours indicate their find contexts: grey archaeological layer IV; light blue layer IV/III; dark blue archaeological layer IIIa; blue archaeological layer III, and turquoise archaeological layer II. 
As is clear from the table the two samples from the same antler artefact gave differing results, by $258{ }^{14} \mathrm{C}$ years, with the AAR-sample being younger and more closely correlating to the related wooden handle (although with a difference of $92{ }^{14} \mathrm{C}$ years, $c f$. Philippsen 2019). Although, if the handle is contaminated with modern carbon, perhaps the older KIA-53778 date is more reliable. The processes at play here, and reasons for the differing dates from the one tool, are not yet completely understood. Theoretically, reasons related to PVA-contamination, slight differences in lab procedures or other unknown factors could play a role. Further investigations are necessary to understand the processes behind these results.

\section{A detailed discussion of the samples and site chronology}

Here, the multiple chronologies will be compared to each other, and discussed in relation to the sedimentation sequence and archaeological finds from the contexts, in an effort to understand a more general chronology of the site.

\section{Archaeological layer IV}

The first occupation phase in the site's history relates to layer IV in both trenches. Archaeological finds from the context have been typologically and technologically interpreted as belonging to the early Butovo technocomplex. At the early stage of this habitation phase, people had settled on the shoreline of the ancient lake.

The sediment samples from layer IV generally suggest an older and shorter chronology (c. 10500 to $9200 \mathrm{cal} \mathrm{BC}$ ) compared to the artefact samples $(c$. $10000-8700 \mathrm{cal} \mathrm{BC}$ ). Ecofacts from layer IV have not been dated and can thus not be compared. A closer look at the individual samples shows that the start and end of these chronologies are rather imprecise, mainly due to the many plateaus on the calibration curve in the early Holocene.

One sediment sample (GIN-10112 II) sets the start of the sediment chronology to 10 500-9800 cal BC. If this lone sample is considered an outlier, the sediment chronology more closely matches the starting point of the artefact-based chronology. However, the oldest artefact sample (KIA-53779) also falls within a plateau on the calibration curve, making it less precise. Nevertheless, the early sediment samples could be viewed as support for such an early start to the phase. If the early artefact and sediment samples are considered reliable, the site was first settled already during the end of the Younger Dryas.

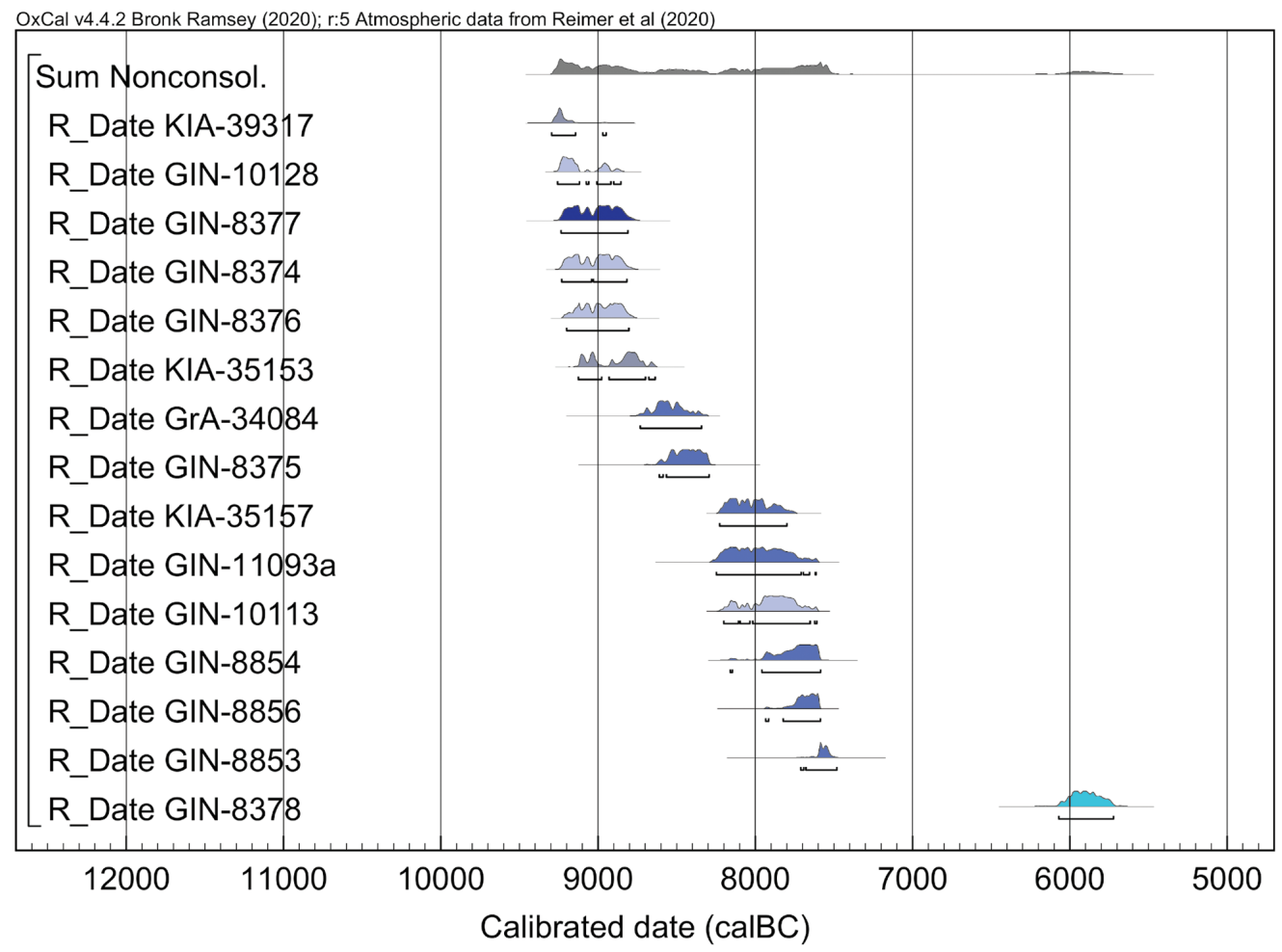

Fig. 9. Calibrated non-consolidated samples from the site. The colours indicate their find contexts: grey archaeological layer IV; light blue layer IV/III; dark blue archaeological layer IIIa; blue archaeological layer III, and turquoise archaeological layer II. 
If we assume that these samples are not reliable, the occupation should instead have started in the early Preboreal, around 9400-9200 cal BC, as suggested by three rather precisely dated artefact samples; KIA39317 (trench 2), KIA-35152 and KIA-53778 (trench $3)$.

The remaining artefact samples from layer IV (AAR22232, KIA-39316 and KIA-35153) date to 9200$8600 \mathrm{cal} \mathrm{BC}$, a time which is also characterized by a calibration curve plateau, again making the end of the occupation phase imprecise. While these samples are all AMS-dated, the latter is at risk of modern contamination. All the AMS-dated samples, except for the one just mentioned, were also consolidated using PVA. The dates AAR-22232, KIA-39316 and KIA-35153 also date to the same time as sediments and artefacts from the overlaying layers IIIa and IV/III (see below), which could indicate that they are unreliable. It could also be an indicator that the temporal difference between the two layers is small.

Due to rising water levels, people had to move away from the shoreline and the artefacts and sediments relating to archaeological layer IV were subsequently submerged in gyttja deposits.

\section{Archaeological layer IIIa and sediment layer between IV/III}

During a temporary water regression during the Preboreal, the site was again inhabited, this time by people related to the Ienovo technocomplex (Zhilin,
Matiskainen 2003). It is likely that a small difference in age is not observable in this part of the chronology due to the long calibration curve plateau at this time. This is assumed because of the stratigraphic sequence as well as a difference in typology between the archaeological layers. Dating more (typo-chronological characteristic) samples from layer IIIa could help determine the age of the layer in relation to adjacent contexts.

The same can be argued about the wooden stakes from trench 2, sediment layer IV/III. The samples (GIN-8374, GIN-8376) were found in horizontal positions, stratigraphically located above the level of layer IV and in the same level as the finds from layer IIIa. Their calibrated dates fall within the same plateau as the sample from layer IIIa. Nonetheless, it cannot be excluded that these samples are related to the habitation mentioned above, by people related to the Ienovo technocomplex.

One ecofact sample from trench 3 (GIN-10113, a thick branch) pierced several layers, perhaps as a result of a tree fall. It is younger than the sediment and rest of the finds, which indicates that it represents a younger intrusion into older layers.

\section{Archaeological layer III}

After another period of rising water levels, by the nearby lake, continuous habitation in the area around the lake and artefacts related to archaeological layer III are accumulated in the water. Pollen indicates

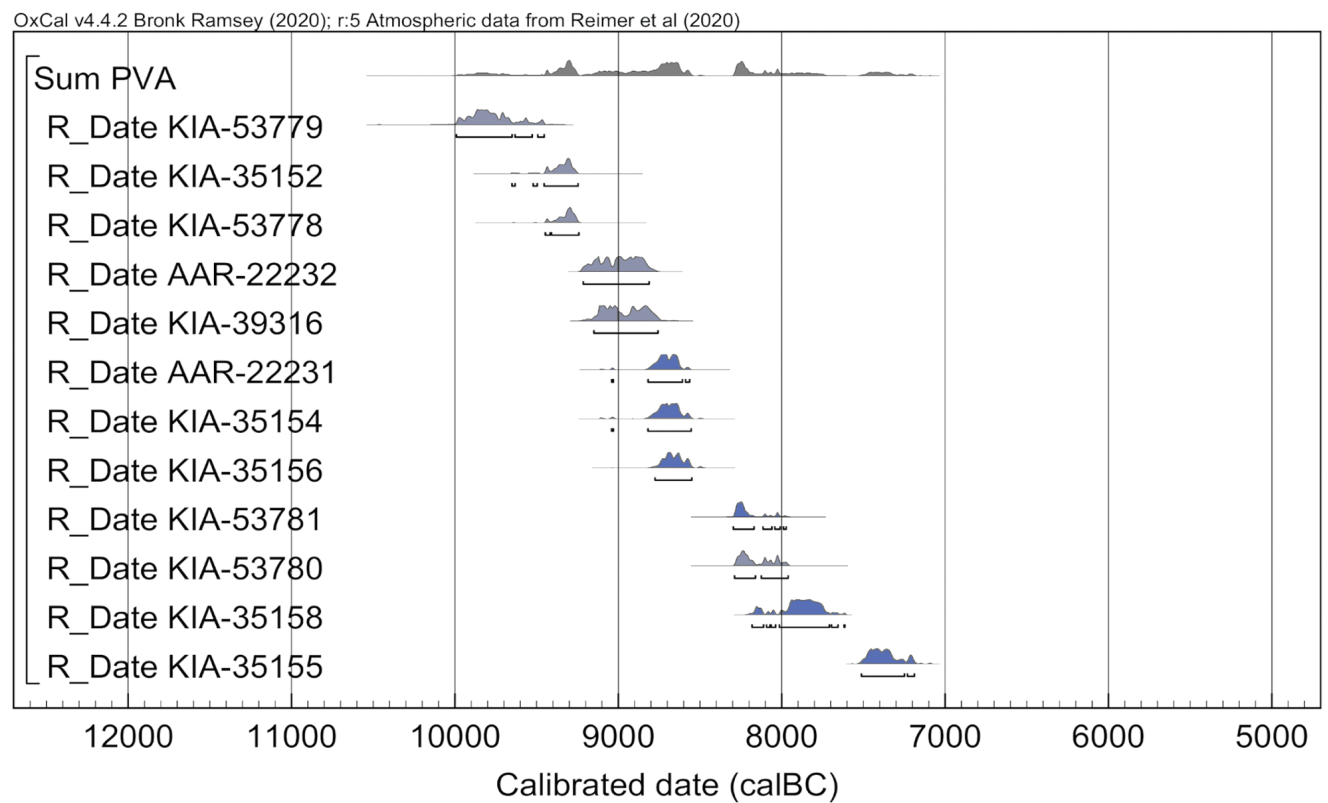

Fig. 10. Calibrated consolidated samples from the site. The colours indicate their find contexts: grey archaeological layer IV; light blue layer IV/III; blue archaeological layer III. 


\begin{tabular}{|lcccccccc}
\hline Lab no. & Part of artefact & Trench & Position & Satrat. & Uncal. BP & $\begin{array}{c}\text { Cal BC } \\
\text { (95.4\%) Start }\end{array}$ & $\begin{array}{c}\text { Cal BC } \\
\text { (95.4\%) End }\end{array}$ & $\begin{array}{c}\text { PVA- } \\
\text { treated }\end{array}$ \\
\hline KIA-35153 & handle & 3 & square 302 & Cult. lay. IV & $9505 \pm 47$ & 9126 & 8638 \\
\hline $\begin{array}{l}\text { AAR-22232 } \\
\text { (further outside) }\end{array}$ & 3 & square 157 & Cult. lay. IV & $9597 \pm 43$ & 9215 & 8812 & yes \\
\hline KIA-53778 & $\begin{array}{c}\text { antler } \\
\text { (further inside) }\end{array}$ & 3 & square 157 & Cult. lay. IV & $9855 \pm 50$ & 9447 & 9242 & yes \\
\hline
\end{tabular}

Tab. 3. Three samples from the same elk antler socket and related wooden handle.

that this occurred in the second half of the Preboreal (according to samples from trench 3 ) and in the early Boreal (according to samples from trench 2) (Aleshinskaya 2001).

The technology and typology of the artefacts from layer III indicate that they are related to the Middle Butovo technocomplex (Zhilin, Matiskainen 2003). The artefact dates from this layer, in trench 2, suggest a chronology spanning 7900-7500 cal BC. A similar pattern is observable in the sediment dates from the same context, which span the time between 8300 and $7600 \mathrm{cal} \mathrm{BC}$.

The artefact samples from the layer in trench 3 instead propose a slightly longer chronology than in trench 2, here stretching from 8800 to $7600 \mathrm{cal} \mathrm{BC}$. One sample (KIA-35155) with a younger date is discussed below. Interestingly, the samples appear to cluster into several sub-phases. However, this is probably an effect of the many calibration curve plateaus during this time span, although the presence of some temporary hiatus within this long time period is probable. Nonetheless, it is likely that the site was more or less continuously or repeatedly settled from the second half of the Preboreal up to the middle of the Boreal period. This is also confirmed by pollen data.

A closer look at some of the artefact samples indicates that habitation at the site may also have taken place during harsher climate conditions. The first five artefact dates fall within a plateau located in the curve around $8800-8300 \mathrm{cal} \mathrm{BC}$. Another couple of dates (KIA-53781 and KIA-53780) fall within the global cold spell around the $7^{\text {th }}$ Bond-event (Bond et al. 1997) around 8300-8100 cal BC. After the Bondevent, another four dates cluster within a plateau in the calibration curve, between $8200-7600 \mathrm{cal} \mathrm{BC}$, followed by another steeper part of the curve where we also find activity on the site (samples GIN-8853) at $7700-7500 \mathrm{cal} \mathrm{BC}$.

The youngest sample from layer III (KIA-35155) dates to sometime around $7500-7200 \mathrm{cal} \mathrm{BC}$, and is also located within a calibration curve plateau. It is significantly younger than the other samples in trench 3 , which could indicate that it is a later intrusion. An archaeological layer dated to the second half of the Boreal period was excavated in trench 1 (Zhilin 2002), and perhaps this sample relates to that occupation.

\section{Archaeological layer II}

The Neolithic layer II is dated via two sediment dates and one artefact date, all from trench 2, to a time span around 6600-5700 cal BC. Typologically distinct finds relating to the Upper Volga culture were found in the same context. One of the samples (GIN10108 II) also falls within an extensive calibration curve plateau, making it imprecise. More dates from this archaeological layer would provide a better chronological base for this Neolithic occupation phase.

Even though many of the dates fall within plateaus in the calibration curve, which inherently lead to less reliability, there are nonetheless clear signs of longlasting or repeated visits and activities in the area of the site throughout the Early Holocene.

\section{The role of AMS-dated and non-consolidated samples from Stanovoye 4}

After calibration, there is no significant difference in the precision of the AMS-dated samples compared to the conventionally dated samples, mainly due to the character of the calibration curve for the early Holocene.

However, the comparison between AMS-dated samples and conventionally dated samples showed that certain contexts and sample materials have been prioritized during dating. This creates a skewed general chronology for the site, since the more reliable (AMS-dated) samples all come from layers IV and III. Meanwhile, layers IIIa and II are not represented at all, and therefore do not contribute to the understanding of the site chronology as reliably as samples from other contexts. Although it should be noted that the conventionally dated samples, from layers 
IIIa, IV/III and II, tend to generally follow the chronologies suggested by the AMS-dates, which indicates that their slightly less reliable nature (due to their dating method) plays a smaller role in this instance. Nonetheless, a more detailed chronology of Stanovoye 4 can only be possible with further AMS-dating of reliable samples along with the further development of the calibration curve for this time period.

Two samples (KIA-39317, GrA-34084) are AMS-dated but not consolidated, which would make them the most reliable samples from the site. They were also not affected by modern or ancient processes like improper storage and reservoir effects. This puts them in a unique position for comparison with the other samples. Nonetheless, these samples do not appear to stand out from the chronology created by the rest of the samples. On the contrary, they fit well into the chronologies suggested by the artefact samples/ AMS-dated samples. This would indicate that the consolidated samples, which underwent cleaning procedures in the labs before dating, seem to be unaffected by the PVA. However, any small differences in age due to PVA-contamination would perhaps go unnoticed due to the multitude of calibration curve plateaus. Needless to say, further testing for PVA-contamination on relevant samples would be useful in order to resolve this issue.

\section{Conclusion}

In this contribution we discussed the many types and common characteristics, of ${ }^{14} \mathrm{C}$-dated samples that are readily available from sites excavated only a few decades ago. It has become clear that the use of slightly older assemblages can be a challenge, due to the constant development of methods and techniques within the field of conservation and radiocarbon dating. Samples taken under current best practices should, and can, still be useful for furthering the understanding of prehistory. Therefore, it is of little gain to simply consider them 'bad' by modern standards and discard them from use. This includes samples that were consolidated using PVA or samples of certain sample materials. It is our opinion that it is better to work with what we have rather than discarding information, in order to better understand the site under the given circumstances. This is of special interest for studies of legacy materials.

In this article, we also set out to investigate the possible effect of PVA-contamination on a selection of the samples from the site, from a strictly archaeological perspective. Although recent studies have shown that PVA is more difficult to remove in the lab than was previously understood, the samples from Stanovoye 4 do not appear to be affected by any remaining PVA contamination, as based on their close correlation to the non-consolidated samples. However, extensive plateaus in the calibration curve for this time make detailed comparisons complicated. Furthermore, these are only initial indications based on a small number of comparable samples. More studies focused on the effects of PVA-contamination should thus be done to confirm or refute these results. The further dating of non-consolidated bone and antler samples from the Stanovoye 4 site, as well as other organic materials such as resin, would also be beneficial for understanding the chronology of the site in general.

The chronologies suggested by various fractions of radiocarbon samples from the site Stanovoye 4 support a joint timeline which includes long standing traditions and a continuous site history that lasts almost 3000 years. The oldest archaeological layer IV on the site relates to the settlement by people related to the Early Butovo technocomplex, and took place between $c$. 10 000-9500 cal BC. After some hiatus, and shorter visits on the site by people linked to the Ienovo technocomplex, the site is again more continuously in use by people in relation to the Middle Butovo technocomplex. Artefacts made and implemented by these people are found in layer III and date to between 8800 and (definitely) $7600 \mathrm{cal} \mathrm{BC}$, possibly even until $c .7200 \mathrm{cal} \mathrm{BC}$. Although a broad chronology for the site has been constructed, many details remain unclear, due to the complex calibration curve during the early Holocene.

Furthermore, it has been highlighted that certain contexts of the site have been prioritized for AMSdating and consolidation, while others are hardly represented at all. More dating efforts are needed from layers IIIa and II in order to reach a more holistic chronological understanding of the site. 


\section{References}

Alexandrovskiy A. L., Alexandrovskaya E. I., Zhilin M. I., and van der Plicht J. 2009. Mesolithic human bones from the Upper Volga Basin: Radiocarbon and trace elements. Radiocarbon 51(2): 637-645.

https://doi.org/10.1017/S0033822200055983

Aleshinskaya A. S. 2001. Paleographic conditions of ancient people settling in Mesolithic of Volga-Oka interfluve (paleological data). Unpublished $\mathrm{PhD}$ thesis abstract. Moscow. Moscow State University. (in Russian)

Brock F., Dee M., Hughes A., Snoeck C., Staff R., and Bronk Ramsey C. 2018. Testing the effectiveness of protocols for removal of common conservation treatments for radiocarbon dating. Radiocarbon 60(1): 35-50.

https://doi.org/10.1017/RDC.2017.68

Bronk Ramsey C. 2009. Bayesian Analysis of Radiocarbon Dates. Radiocarbon 51(1): 337-360.

https://doi.org/10.1017/S0033822200033865

Bronk Ramsey C., Higham T., and Leach P. 2004. Towards High-Precision AMS: Progress and Limitations. Radiocarbon 46(1): 17-24.

https://doi.org/10.1017/S0033822200039308

Damlien H. 2016. Eastern pioneers in westernmost territories? Current perspectives on Mesolithic hunteregatherer large-scale interaction and migration within Northern Eurasia. Quaternary International 419: 5-16. http://dx.doi.org/10.1016/j.quaint.2014.02.023

Dee M., Brock F., Bowles A., and Ramsey C. 2011. Using a Silica Substrate to Monitor the Effectiveness of Radiocarbon Pretreatment. Radiocarbon 53(4): 705-711. https://doi.org/10.1017/S0033822200039151

Hartz S., Terberger T., and Zhilin M. 2010. New AMS-dates for the Upper Volga Mesolithic and the origin of microblade technology in Europe. Quartär 57: 155-169.

Johnson J. S. 1994. Consolidation of Archaeological Bone: A Conservation Perspective. Journal of Field Archaeo$\operatorname{logy} 21(2)$ : 221-233.

Kankaanpää J., Rankama T. 2014. Fast or Slow Pioneers? A View from Northern Lapland. In Riede F., Tallaavaara M. (eds.), Lateglacial and Postglacial Pioneers in Northern Europe. BAR International Series 2599. Archaeopress. Oxford: $147-159$.

Manninen M. A., Damlien H., Kleppe J. I., + 4 authors, and Persson P. 2021. First encounters in the north: Cultural diversity and gene flow in Early Mesolithic Scandinavia.
Antiquity 95(380): 310-328.

https://doi.org/10.15184/aqy.2020.252

Meadows J., Boudin M., Groß D., Jantzen D., Lübke H., and Wild M. 2019. Radiocarbon dating bone and antler artefacts from Mesolithic Hohen Viecheln (Mecklenburg- Western Pomerania, Germany). In Groß D., Lübke H., Meadows J., and Jantzen D. (eds.), Working at the Sharp End: From Bone and Antler to Early Mesolithic Life in Northern Europe. Untersuchungen und Materialien zur Steinzeit in Schleswig Holstein und im Ostseeraum Band 10. Vachholtz. Kiel/Hamburg: 113-126.

Meadows J., Lozovskaya 0., Bondetti M., Drucker D., and Moiseyev V. 2019. Human palaeodiet at Zamostje 2, central Russia: Results of radiocarbon and stable isotope analyses. Quaternary International 541: 89-103.

https://doi.org/10.1016/j.quaint.2019.07.017

Philippsen B. 2013. The freshwater reservoir effect in radiocarbon dating. Heritage Science 1: 24. https://doi.org/10.1186/2050-7445-1-24

2019. Approaches to determine reservoir effects in elk/ moose. Radiocarbon 61(6): 1889-1904. https://doi.org/10.1017/RDC.2019.124

Rankama T., Kankaanpää J. 2007. The Earliest Postglacial Inland Settlement of Lapland. In Volokitin A. V. (ed.), $\mathrm{Ka}$ mennyi vek evropeiskogo Severa [The Stone Age of northernmost European Russia]. Russian Academy of Sciences, Uralian Section. Komi Scientific Centre, Institute of Languages. Literature and History. Syktyvkar.

Rankama T., Kankaanpää J. 2008. Eastern arrivals in postglacial Lapland: The Sujala site 10000 cal BP. Antiquity 82(318): 884-899.

https://doi.org/10.1017/S0003598X00097659

Reimer P., Austin W., Bard E., + 38 authors, and Talamo S. 2020. The IntCal20 Northern Hemisphere radiocarbon age calibration curve (0-55 cal kBP). Radiocarbon 62(4): 725-757. https://doi.org/10.1017/RDC.2020.41

Sørensen M., Rankama T., Kankaanpää J., + 4 authors, and Glørstad H. 2013. The First Eastern Migrations of People and Knowledge into Scandinavia: Evidence from Studies of Mesolithic Technology, 9th-8th Millennium BC. Norwegian Archaeological Review 46(1): 19-56. https://doi.org/10.1080/00293652.2013.770416

Stevens R. E., Hedges R. E. M. 2004. Carbon and nitrogen stable isotope analysis of northwest European horse bone and tooth collagen, 40,000 BP-present: Palaeoclimatic in- 
terpretations. Quaternary Science Reviews 23: 977- 991. https://doi.org/10.1016/j.quascirev.2003.06.024

Taylor R. E., Bar-Yosef 0. 2014. Radiocarbon Dating. An Archaeological Perspective. Second edition. Left Coast Press, Inc. Walnut Creek.

Zaretskaya N. E., Ponomareva V. V., Sulerzhitsky L. D., and Zhilin M. G. 2001. Radiocarbon studies of peat bogs: an investigation of south Kamchatka volcanoes and Upper Volga Archaeological sites. Radiocarbon 43(2B): 571-580. https://doi.org/10.1017/S0033822200041229

Zaretskaya N. E., Zhilin M., Karmanov V. N., and Uspenskaya 0. N. 2005. Radiocarbon Dating of Wetland MesoNeolithic Archaeological Sites within the Upper Volga and Middle Vychegda. Geochronometria - Journal on Methods and Applications of Absolute Chronology 24: 117131.

Zhilin M. 2002. Stratigrafiya i planigrafiya mnogosloynogo poseleniya Stanovoye $4 \mathrm{v}$ Verkhnem Vovolzh'ye. Tverskoy Archeologichesky Sbornik 5: 107-116. (in Russian)

2003. Early Mesolithic peat bog sites on the Upper Volga. In Bauerochse A., and Haßmann H. (eds.), Peatlands. Archaeological sites - archives of nature - nature conservation - wise use. Proceedings of the Euro- pean Peatland conference 2002 in Hannover, Germany. Hannover. Verlag Marie Leidorf. Rahden: 48-61.

2004. Prirodnaya sreda $i$ khozyaystvo mezoliticheskogo naseleniya tsentra i severo-zapada lesnoy zony Vostochnoy Evropy. Moskva. (in Russian).

2007. The early Mesolithic of the Upper Volga: selected problems. In Masojć M., Płonka T., Ginter B., and Kozłowski S. K. (eds.), Contributions to the Central European Mesolithic. Institute of Archaeology. University of Wrocław. Wroclaw: 89-104.

2009. Chronology and Evolution in the Mesolithic of the Upper Volga-Oka interfluve. In Crombé P., van Strydonck M., Sergant J., Boudin M., and Bats M. (eds.), Chronology and evolution within the Mesolithic of North-West Europe. Proceedings of an International Meeting, Brussels, May 30th-June 1st 2007. Cambridge scholars publishing. Newcastle upon Tyne: 451-472.

Zhilin M., Matiskainen H. 2003. Deep in Russia, deep in the bog. Excavations at the Mesolithic Sites Stanovoje 4 and Sakhtysh 14, Upper Volga region. 2003. In Larsson L., Kindgren H., Leffler D., and Akerlund A. (eds.), Mesolithic on the Move. Papers Presented at the Sixth International Conference on the Mesolithic in Europe, Stockholm 2000. Oxbow monograph. Oxford: 694-702.

\section{Appendix - Sample treatment at different labs}

The organic samples from Stanovoye 4 reported in our paper were radiocarbon dated at different times in various labs. The pre-treatments involved in the dating procedure can be found below along with relevant sources.

Leibniz Laboratory for Radiometric Dating and Stable Isotope Research in Kiel (lab-code KIA):

Pre-treatment of the bones and collagen extraction was done in several steps. Firstly, the pieces of crushed, solid bone material $(0,5-2 \mathrm{~mm})$ were defatted using acetone, rinsed with demineralized water and subsequently demineralized in $\mathrm{HCl}(c$. $1 \%)$. Mobile humic acids were removed by taking the previously demineralized bone material and treating it with $1 \% \mathrm{NaOH}\left(20^{\circ} \mathrm{C}, 1 \mathrm{~h}\right)$ and once again with $1 \% \mathrm{HCl}\left(20^{\circ} \mathrm{C}, 1 \mathrm{~h}\right)$. The bone collagen, to be used for dating, was dissolved overnight as gelatine in demineralized water at $85^{\circ} \mathrm{C}$ and $\mathrm{pH}=3$. Insoluble particles were removed using filtration through a $0.45 \mu \mathrm{m}$ pore silver filter. The gelatine solution was then freeze-dried, which is an adaption of the method described by Longin (1971).

Combustion to $\mathrm{CO}_{2}$ was performed in an evacuated quartz tube with $\mathrm{CuO}$ and silver wool at $900^{\circ} \mathrm{C}$. The obtained $\mathrm{CO}_{2}$ was subsequently reduced at $600^{\circ} \mathrm{C}$, using $\mathrm{H}_{2}$ and iron powder as the catalyst. The resulting graphite mixture was pressed into a target holder for AMS measurement.

\section{Geological Institute at the Russian Academy of Sciences (RAS) (lab-code GIN):}

The sediment samples dated in 2005 were subdivided into two fractions, one of which underwent a hot alkaline extraction and the other a cold alkaline extraction. This procedure was designed to separate and recover organic matter that relate to different stages of preservation (details in Zaretskaya et al. 2001). This also resulted in two dates for each sample (I and II). Nataliya E. Zaretskaya et al. (2001) use the age difference between the two measurements as a reflection of the age variation within the 
sediment layer. The warm-extractions were mainly used in the current study. 1

Wood and bone samples were pre-treated and dated using routine procedures used at GIN. Wood samples underwent a standard A-A-A pre-treatment; the samples were first cleaned by standing in hot 5\% $\mathrm{HCl}$, washed with distilled water and subsequently boiled for $20 \mathrm{~min}$ in a $2 \% \mathrm{NaOH}$ solution. Alkali insoluble wood fragments were then digested in hot $5 \% \mathrm{HCl}$ and finally washed with distilled water ( $\mathrm{Za}$ retskaya et al. 2001).

\section{Aarhus AMS centre (lab-code AAR):}

Bone and antler samples were demineralized using $1 \mathrm{M} \mathrm{HCl}$ for several days, until the end of effervescence (complete dissolution of calcium carbonate) and no observed density gradient (calcium phosphate completely dissolved). Humates were then removed using $0.1 \mathrm{M} \mathrm{NaOH}$, with renewed $\mathrm{NaOH}$ until the solution remained colourless, with each base step lasting several hours at $4^{\circ} \mathrm{C}$. After each base/ acid step, samples were rinsed three times with de- mineralized $\mathrm{H}_{2} \mathrm{O}$. Finally, the samples were rinsed three times with a weak HCl-solution $(\mathrm{pH}=2)$, covered with that solution, and heated to $58-80^{\circ} \mathrm{C}$ for 48 hours, until collagen was dissolved. Samples were centrifuged (15 minutes at 2000rpm) and filtered through $0.45 \mu \mathrm{m}$ syringe filters, before being freeze dried (Philippsen 2019).

\section{Groningen AMS lab (lab-code GrA):}

Collagen from the bones was extracted using a modernized version of the Longin method (Longin 1970). The collagen was then combusted, purified and transferred into graphite (Aerts-Bijma et al. 2001). This graphite was pressed into target holders for the AMS ion source. The AMS measured the isotope ratios ${ }^{14} \mathrm{C} /{ }^{12} \mathrm{C}$ and ${ }^{13} \mathrm{C} /{ }^{12} \mathrm{C}$ of the graphite, from which the conventional ${ }^{14} \mathrm{C}$ age is determined (van der Plicht et al. 2000). The stable isotope ratios $13 \mathrm{C} / 12 \mathrm{C}$ and $15 \mathrm{~N} / 14 \mathrm{~N}$ were measured for the same collagen dated by AMS. These stable isotope ratios were measured by an elemental analyser, combined with a mass spectrometer (Aerts-Bijma et al. 2001; Alexandrovskiy et al. 2009).

\section{References - Appendix}

Aerts-Bijma A. T., van der Plicht J., and Meijer H. A. J. 2001. Automatic AMS sample combustion and CO2 collection. Radiocarbon 43(2A): 293-298.

https://doi.org/10.1017/S0033822200038133

Alexandrovskiy A. L., Alexandrovskaya E. I., Zhilin M. I., and van der Plicht J. 2009. Mesolithic human bones from the Upper Volga Basin: Radiocarbon and trace elements. Radiocarbon 51(2): 637-645.

https://doi.org/10.1017/S0033822200055983

Beta Analytical (n.d.). Beta Analytic Standard Pretreatment Protocols. Sections "Acid/alkali/acid" and "Acid/ alkali/acid - solubles". Retrieved April 1, 2021, from https:// www.radiocarbon.com/pretreatment-carbon-dating.htm

Nilsson M., Klarqvist M., Bohlin E., and Possnert G. 2001. Variation in ${ }^{14} \mathrm{C}$ age of macrofossils and different fractions of minute peat samples dated by AMS. The Holocene 11 (5): 579-586.

https://doi.org/10.1191/095968301680223521
Philippsen B. 2019. Approaches to determine reservoir effects in elk/moose. Radiocarbon 61(6): 1889-1904. ttps://doi.org/10.1017/RDC.2019.124

Longin R. 1970. Extraction du collagène des os fossils pour leur datation par la méthode du carbone 14. Unpublished PhD thesis. Université de Lyon. Lyon

1971. New Method of Collagen Extraction for Radiocarbon Dating. Nature 230(5291): 241-242. https://doi.org/10.1038/230241a0

van der Plicht J., Wijma S., Aerts A. T., Pertuisot M. H., and Meijer H. A. J. 2000. The Groningen AMS facility: status report. Nuclear Instruments and Methods in Physics Research B 172(1-4): 58-65.

Zaretskaya N. E., Ponomareva V. V., Sulerzhitsky L. D., and Zhilin M. G. 2001. Radiocarbon studies of peat bogs: an investigation of south Kamchatka volcanoes and Upper Volga Archaeological sites. Radiocarbon 43(2B): 571-580. https://doi.org/10.1017/S0033822200041229

1 A similar approach as described by Zaretskaya et al. (2005) has been presented as a manner of removing mobile secondary organics from the bulk sediment (Beta Analytical n.d., sections 'Acid/alkali/acid' and 'Acid/alkali/acid - solubles'). These mobile organics have been shown to often reflect younger fractions of the soil (Nilsson et al. 2001, and sources therein) which, if not removed can result in a modern contamination. Due to the higher risk of more modern carbon in the mobile organics, the cold-extraction samples from Stanovoye were considered less reliable than warm-extraction samples, and thus excluded when the two fractions were non-consistent. I the case that samples correspond to the same age, samples from both extraction methods remain in the study. 